\title{
The Study of Stress Coping and Basic Beliefs of Students Depending on their Superstition Level
}

\author{
Rezeda R. Akbirova* (a), Ildar R. Abitov (b), Inna M. Gorodetskaya (c), Svetlana \\ V.Velieva (d) \\ (a), (b) Kazan Federal University, 420008, Kazan (Russia), 18 Kremlyovskaya street, \\ akbrezeda@yandex.ru \\ (c) International Psycho-Educational Projects Association,Tel-Aviv (Israel),innamgor@gmail.com \\ (d) Chuvash State Teachers-Training University, 428034, Cheboksary (Russia), 45 \\ Moskovsky prospect, stlena70@mail.ru
}

\begin{abstract}
The article addresses some aspects of coping behavior. It presents empiric findings concerning correlations between superstitiousness and paranormal beliefs and students' coping strategies. It was found that students with a high superstition index have more manifested belief in paranormal phenomena (traditional religious belief, belief in witchcraft, spiritism, psi-abilities, and extraordinary forms of life). They also tend to use the coping strategy "positive reassessment", i.e. they try to find positive aspects in the difficult situations and are able to change their attitude towards it. It was also revealed that students with low superstition index have more pronounced beliefs concerning luck and control. They believe that they can control the events that occur, and at the same time they believe in good luck. It was supposed that students with higher manifestation of superstitiousness use it as a compensation mechanism for their less developed confidence in the ability to control their lives and weaker faith in their personal luck. Significant statistical relationships have been detected between superstitions and paranormal beliefs, on the one hand, and behavior in a stressful situation (coping strategies), on the other hand.
\end{abstract}

Keywords: superstitiousness, superstitions, coping behavior, stress

(C) 2020 Rezeda R. Akbirova, Ildar R. Abitov, Inna M. Gorodetskaya, Svetlana V. Velieva

This is an open access article distributed under the terms of the Creative Commons Attribution License (CC BY 4.0), which permits unrestricted use, distribution, and reproduction in any medium, provided the original author and source are credited.

Published by Kazan federal university and peer-reviewed under responsibility of IFTE-2020 (VI International Forum on Teacher Education)

\footnotetext{
* Corresponding author. E-mail: akbrezeda@yandex.ru
} 


\section{Introduction}

Students face many study-related problems in their university life. Stress/stress coping is considered to be one of them. University studying is one of the most intellectually and emotionally stressful activities (Karyakina, 2010). It is accompanied by emotional experiences, goal achieving and overcoming difficulties, especially during examinations. Educational stress factors cause emotional responses that negatively influence the body and make difficulties to successful learning. Coping strategies play an important role in overcoming stress. Coping strategies are consciously used techniques of overcoming difficult situations and conditions that cause those situations.

\section{Purpose and objectives of the study}

The purpose of the study is to reveal the peculiarities of coping behavior and basic beliefs about themselves and the world of students with high and low superstitiousness. We suppose that superstitiousness is manifested in behavior through definite coping strategies (having a substantive connection to superstitiousness), and in cognitive sphere - in definite beliefs about themselves and the world around and in paranormal conceptions.

\section{Literature review}

During the last 40 years a wide range of studies focused on coping behavior have been carried out in different countries and, since the 90's of the XX century, in Russia (Lazarus \& Folkman, 1984; Belan, 2004; Volkova et al., 2005; Dementiy, 2004; Kryukova, 2010; Lykova, 2004; Ilyukhin, 2011).

Kryukova (2010) defines coping behavior as teleonomic social behavior that allows overcoming difficulties with techniques that are relevant both to personal peculiarities and situational specifics.

Scientific literature says that when people feel insecurity, high psychological stress, low possibility to control the situation (Keinan, 1994; Malinowski, 1954; Whitson \& Galinsky, 2008), and when it is necessary to be highly efficient (Sarason, 1984; Treasure et al., 1996), they are mostly often become superstitious.

Therefore, it is not surprising that there is a range of studies that indicate that two groups often show superstitious beliefs - sportsmen and students. These two groups regularly perform tasks and get are being assessed (Albas \& Albas, 1989; Womack, 1992). 
Superstitiousness can be considered as an individual's worldview characteristic that specifies his attitude towards reality. The term "faith" is closest to this category in modern psychology. Dvoynin (2011) defines faith as "inner attitude of an individual that mythologizes a person's disposition to reality". We consider superstitiousness a special case of faith, as it implies a person's inner attitude to reality. Superstitiousness is a system of beliefs that includes a person's conviction that there exist supranatural powers that can affect people, techniques to influence in a supernatural way (witchcraft, basilisk-glance, evil spirits, etc.) and a cause-and-effect link between neutral events (black cat, number 13, etc.) and negative consequences in the future (bad luck, illnesses, etc.), that may be avoided with the help of some protection rituals. This conviction is accompanied by willingness to perform ritual acts and following definite culturally relevant rules ("signs").

Many scholars regard superstitions and paranormal beliefs as a kind of healthy adaptive behavior. These authors suppose that superstitious beliefs are inevitable (or even desirable) by-product of adaptive learning strategies (Beck \& Forstmeier, 2007; Damisch et al., 2010).

Boden (2015) indicates adaptive, positive character of supernatural, religious, spiritual beliefs and destinism. His findings show that supernatural beliefs provide understanding and gratification. Adaptive character of beliefs (regardless of their type) is linked to psychological benefits (higher life satisfaction, emotional clarity and positive emotions, decrease of negative feelings, depression and stress). The researcher concludes that supernaturalism in general and specific beliefs in particular are potentially adaptive and bring psychological benefits (Boden, 2015).

Many scholars focus on three aspects of superstitiousness: emotional, cognitive and behavioral.

Lévy-Bruhl considers superstitions as special type of conceptualizations that are transferred across generations by socio-psychological mechanisms of psychic contagion and suggestion. He indicates that superstitions join cognitive and emotional elements (cited in Saenko, 2006).

Lebedev notes that emotional factors such as death anxiety, autophobia, crisis experiences, widely spread during difficult socio-economical periods of change influence superstitions incidence (cited in Saenko, 2006).

Olshanskiy (2001) emphasizes defensive character of superstitions. He considers superstitions as a way of self-help that allows anxious people keeping sense of control in difficult situations and reduce anxiety when other self-regulation techniques are inaccessible and ineffective. 
Ismodenova (2013) considers that superstitions are manifested on the level of behavior - people perform ceremonies and rituals, use talismans, magic gestures, etc. The results of the study show the following main reasons for using superstitions: fear, anxiety, self-distrust, lack of confidence in the correctness of decisions, and desire to foresee the consequences of their actions. Ismodenova (2013) states that supernaturalism helps a person to build self-confidence, confidence in the future and in the outcomes of his own actions.

Saenko (2006) indicates three aspects of superstitions: cognitive, affective-motivational and behavioral.

Cognitive aspect of superstition includes cognitive processes that provide recognition and categorization of unknown events and situations and help to try to foresee probable consequences and outcomes to develop definite behavior towards these events and situations.

Affective-motivational component come with emotional states that occur in potentially dangerous or desirable situations that correspond to current needs of a person.

Behavioral component, in its turn, comprises ritual and symbolic actions aimed at protecting a person in cases of imminent danger, at preventing an undesirable and at giving rise to desirable events (Saenko, 2006).

Saenko (2006) thinks that irrational fears may underlie superstitions. A person wants to defend his consciousness from anxiety and fear with the help of omens and superstitions. Behavioral aspect of superstitions allows controlling people's social behavior.

We believe that considering cognitive, emotional (affective-motivational) and behavioral structural components of superstitiousness is heuristically valuable and makes it possible to study superstitiousness within the context of psychology of personal relationships as a special type of relations towards environment that creates illusion of understanding when there is a lack of information and illusion of control in the situations of uncertainty when there occur uncontrolled phenomena or phenomena with limited possibility to control.

In the given study we focused on cognitive and behavioral aspects of superstitiousness. We consider preferred coping-strategies as indicators of behavioral component of superstitiousness. It was supposed that more superstitious people prefer strategies aimed at avoidance of problem solving and no direct interaction with stressors, such as escape, distancing and positive reassessment. Personal beliefs were chosen as markers of cognitive aspect of superstitiousness. It was supposed that more superstitious people have lower 
values of basic beliefs concerning themselves and the world. Superstitious beliefs in this case act as compensators of lack of control over life situations, low self-esteem and idea of unfriendliness and unfairness of the world.

In spite of expressed interest in studying coping strategies and superstitiousness there are very few researches of their correlations in psychology. In particular, there are no studies of peculiarities of stress coping and basic beliefs of students with different superstitiousness level.

\section{Methodology}

The following empiric methodology was used: Paranormal Belief Scale by Tobacyk (adapted by Grigoriev, 2015), Superstitiousness Inventory (Abitov, 2016), Ways of Coping Questionnaire by Folkman \& Lazarus adapted by Kryukova (2010), The Basic Beliefs Scale by Janoff-Bulman's and adapted by Padun and Kotelnikova (2008).

The empiric study was carried out in the Internet. All questionnaires were put into Google-forms and sent to respondents via e-mails.

The population of the study consisted of undergraduate students from Kazan (Volga region) Federal University, Novosibirsk state pedagogical University, Chuvash state University, and Yaroslavl State University. In total, the study involved 204 students divided into two groups according to their superstition manifestations according to the sub-scale "Superstition" of The Paranormal Belief Scale by Tobacyk (Grigoriev, 2015). The first group included young people with high superstition index (107 people), and the second group consisted of students with lower than the average superstition index (61 people).

The Mann-Whitney U-test was used to find differences between the studied groups, and the Spearman correlation coefficient was used to reveal correlations between various parameters.

\section{Results}

It was found that respondents with high level of superstition show higher values of the following scales: “ Traditional Religious Belief” ( $\mathrm{p} \leqslant 0,001, \mathrm{U}=1915,5)$, «Psi» $(\mathrm{p} \leqslant 0,001 ; \mathrm{U}=1798,5)$, Witchcraft» $(\mathrm{p} \leqslant$ 0,001; $U=1672)$, «Spiritualism» ( $p \leqslant 0,001 ; U=1894,5)$, «Extraordinary Life Forms» $(p \leqslant 0,01 ; U=2376)$, «Precognition» $(\mathrm{p} \leqslant 0,001 ; \mathrm{U}=1192,5)$ of Paranormal Belief Scale by Tobacyk, and of the “ Superstitiousness" scale of Inventory by Abitov ( $\mathrm{p} \leqslant 0,001 ; \mathrm{U}=0,600)$. This group also shows a more manifested coping strategy "Positive reassessment" ( $p \leqslant 0,045, \mathrm{U}=2658,5)$. The group with low 
superstition index shows more expressed beliefs concerning luck $(\mathrm{p} \leqslant 0,033, \mathrm{U}=2617)$ and control $(\mathrm{p} \leqslant$ $0,04, \mathrm{U}=2621)$.

The Spearman rank correlation coefficient was used to reveal correlations between the parameters.

Both sample groups show significant direct correlations of superstitiousness index on the inventory by Abitov and superstition scale by Tobacyk ( $r=0,406 ; \mathrm{p} \leqslant 0,001$ и $\mathrm{r}=0,439 ; \mathrm{p} \leqslant 0,001$, correspondently with respondents with high and low superstition). In the low superstition group statistically significant direct correlations of Superstitiouness parameter (by Abitov inventory) with Spiritualism, Traditional Religious Belief, Psi, Witchcraft, Precognition and Extraordinary Life Form beliefs (by Tobacyk inventory). In the high superstition group these parameters have no statistically significant correlations.

Besides, respondents with high superstition indexes show statistically significant direct correlations of superstitiousness (Abitov Inventory) and stress coping strategy "Confrontation” ( $\mathrm{r}=0,295 ; \mathrm{p} \leqslant 0,021)$. Superstition parameter (Tobacyk Inventory) directly correlates with "Control Belief” (r=0,274; $\mathrm{p} \leqslant$ $0,033)$.

In the low superstition group superstitiousness parameter (Abitov Inventory) has a direct significant correlation with conviction that the world is fair $(\mathrm{r}=0,208 ; \mathrm{p} \leqslant 0,032)$, and coping strategies "Distancing ” $(\mathrm{r}=0,293 ; \mathrm{p} \leqslant 0,02)$, «Escape» $(\mathrm{r}=0,318 ; \mathrm{p} \leqslant 0,01)$ and «Positive reassessment» $(\mathrm{r}=0,203 ; \mathrm{p} \leqslant 0,036)$.

\section{Discussions}

The findings indicate that respondents with high level of superstition believe that there exist people with extraordinary capabilities that allow influencing things and other people with the help of mental power, and are more religious than those who have low superstition level.

Students with higher manifestation of superstitiousness have less developed belief in the ability to control their lives and in their good luck. We believe that superstitiousness can be considered as a way to compensate low level of self-confidence and weak belief in the personal good fortune. Positive correlation between superstitiousness level and beliefs concerning control in the group of highly superstitious students may indicate the same fact. The more superstitious the students are the more they feel able to control their lives.

Respondents with more expressed superstition tend to pay special attention to events in their lives, to seek and find positive aspects in the current situation. This group overcomes difficulties by changing the attitude 
towards the situation and finding positive aspects. Students with high superstition level overpass negative emotions by positive reassessment of a problem and looking at it as at as stimulus for personal growth. The negative side of such coping behavior is high probability of underestimation of active solving of a problem. Superstitious ideas of students may act as regulators of different types of behavior in stressful situations, including the above-mentioned positive reassessment. Therefore, cognitive component of superstitiousness in the high superstition group comprises beliefs in witchcraft, supernatural beings, metempsychosis, possibility to communicate with the souls of dead people, superpowers (like levitation and telekinesis), precise precognition and fortune-telling and traditional religious beliefs. Behavioral component includes actions aimed at reassessment of the situation, finding positive aspects and drawing lessons from it (inter alia in religious context).

Respondents with low superstition level, on the one hand, are convinced that they can control thing that occur, and on the other hand, they believe in their good luck. This group is disposed to give selfinstructions and to psych themselves up for emotional and behavioral self-control. They are sure that it is almost always possible to achieve maximally advantageous results and to minimize failure. Thus, low level of superstition is compensated with the respondents' conviction in the capabilities to affect the situation and control it, as well as with belief in their good luck and that everything turns out to be an advantage. These ideas may be presented as self-confidence and confidence in personal good luck.

Significant correlations between superstitiousness index according to Abitov's Inventory (2016) and the superstition parameter of Tobacyk Scale (Grigoriev, 2015) in both groups confirms the inner validity of the inventory developed by Abitov (2016).

In the low superstition group superstitions and various paranormal beliefs have correlations with such strategies as "Distancing", "Positive reassessment", "Escape" and with the belief that the world is fair. The more superstitious the students from this group are the more often they use stress coping aimed at avoiding the problem, denial and distraction, and reducing its importance. All the more reason they are sure that the world is fair and people get what they deserve. This correlation may reflect one of superstitiousness's functions that has to do with overcoming stressful situations by practicing rituals, omens and beliefs.

\section{Conclusion}

Therefore, the empiric findings allow making the following conclusions:

1. Cognitive component of superstitiousness of highly superstitious students is manifested by their belief in "signs", "omens" and by their belief in different paranormal phenomena (traditional religious 
belief, witchcraft, spiritualism, psi, extraordinary life forms). Cognitive component of superstitiousness among the highly superstitious students includes low level of beliefs in control and in the personal good fortune.

2. Manifestations of superstitiousness can be considered as a way to compensate low level of selfconfidence and weak belief in good luck within the group of students with higher level of superstitiousness.

3. Behavioral component of superstitiousness of highly superstitious students is manifested by the coping-strategy "Positive reassessment", i.e. they tend to find positive aspects in difficult situations they face, change their attitude towards stressful situations and draw morals.

4. Students with low superstition indexes are more convinced in their good luck and possibilities to control. They believe that they are able to control things that happen to them and that they are lucky enough. This group is confident in their capabilities and in their good fortune.

\section{Acknowledgements}

The reported study was funded by RFBR, project number 20-013-00644 A.

\section{References}

Abitov, I. R. (2016). Superstitiousness and its correlation with stress. Socio-Economic and Technical Systems: Research, Design, Optimization, 5(72), 10-15.

Albas, D., \& Albas, C. (1989). Modern magic: The case of examinations. Sociological Quarterly, 30, 603613.

Beck, J., \& Forstmeier, W. (2007). Superstition and belief as inevitable by-products of an adaptive learning strategy. Human Nature, 18(1), 35-46. https://doi.org/10.1007/BF02820845

Belan, E. A. (2004). Psychology of control behaviour. Krasnodar: KubGU.

Boden, M. (2015). Supernatural beliefs: Considered adaptive and associated with psychological benefits. Personality and Individual Differences, 86. 227-231. 10.1016/j.paid.2015.06.023

Damisch, L., Stoberock, B., \& Mussweiler, T. (2010). Keep your fingers crossed! How superstition improves performance. Psychological Science, 21, 1014-1020. https://doi.org/10.1177/ 0956797610372631 
Dementiy, L. I. (2004). To the problem of diagnostics of a social context and the strategies of copingbehaviour. Zhurnal prikladnoi psikhologii, 3, 20-25.

Dvoynin, A. M. (2011). Psychology of Believer: Values and Meanings and religious faith of a person. St. Petersburg: Rech.

Grigoriev, D. S. (2015). Adaptation and validation of the Paranormal Belief Scale by J. Tobacyk. Social Psychology and Society, 6(2), 132 - 145.

Ilyukhin, A. G. (2001). Development of coping-strategies at students in situations of intellectual tests. Cand. Psychol. Sci. Diss. Tambov.

Ismodenova, N. N. (2013). Superstitions as a way of living of the educated population groups. Proceedings of Kola research center of the Russian Academy of Science, 6(19), 20-35.

Karyakina, S. N. (2010). Kharakteristika uchebnogo stressa studentov mladshikh i starshikh kursov vysshego uchebnogo zavedeniya [Characteristics of stress in the process of study of junior and senior courses students of higher education establishments]. Scientific Notes of Oryol State University, 2, 210-215.

Keinan, G. (1994), Effects of stress and tolerance of ambiguity on magical thinking. Journal of psychology and Social Psychology, 67, 48-55.

Kryukova, T. L. (2010). Psychology of coping behavior in different periods of life. Kostroma: KSU of N.A. Nekrasov.

Lazarus, R. S., \& Folkman, S. (1984). Stress, Appraisal and Coping. N. Y.: Springer Publishing House.

Lykova, N. M. (2004). Theory of stress and coping. Moscow: MGOU.

Malinowski, B. (1954). Magic, science and religion and other essays. Garden city, NY: Doubleday.

Olshanskiy, D. V. (2001) Mass psychology. Spb.: Piter.

Padun, M. A., \& Kotelnikova, A. V. (2008). The modification of the basic beliefs scale by R. JanoffBulman. Psychological journal, 29(4), 98-106.

Saenko, Y. V. (2006). Psychological aspects of the superstitions studies. Voprosy Psychologii, 6, 85-97. 
Sarason, I.G. (1984). Stress, anxiety, and cognitive interference: Reaction to tests. Journal of psychology and Social Psychology, 46, 929-938.

Treasure, D.C., Monson, J., \& Lox, C.L. (1996). Relationship between self-efficacy, wrestling performance, and affect prior to competition. The Sport Psychologist, 10, 73-83.

Volkova O. N., Kossova E. G., \& Chekhlaty E. I. (2005). A study of the quality of life of healthy people and coping strategies in gender aspect. Vestnik psikhoterapii, 13, 65-75.

Whitson, J.A., \& Galinsky, A. D. (2008). Lacking control increases illusory pattern perception. Science, $322,115-117$.

Womack, M. (1992). Why athletes need rituals: A study of magic among professional athletes. In S.J. Hoffman (Ed), Sports and Religion (pp. 191 - 202). Champion, IL: Human Kinetics. 